\title{
Revisiting the Morphological Variations in Lumbricals of Hand
}

\author{
Khizer Hussain Afroze $\mathbf{M}^{1}$, Sangeeta $\mathbf{M}^{2}$, Varalakshmi K.L ${ }^{3}$ \\ ${ }^{1}$ Assistant Professor, Department of Anatomy, MVJ Medical College \& Research Hospital, Hoskote, Bangalore, Karnataka, India, ${ }^{2}$ Professor \& HOD, \\ Department of Anatomy, MVJ Medical College \& Research Hospital, Hoskote, Bangalore, Karnataka, India, ${ }^{3}$ Associate Professor, Department of Anatomy, \\ MVJ Medical College \& Research Hospital, Hoskote, Bangalore, Karnataka, India.
}

\section{Abstract}

Introduction: The lumbrical muscles are unique in their functions in being only intrinsic muscles which bridges between the palmar and dorsal surface. This unique property endows them in performing fast, alternating movements and fine tuning digit motion. The aim of this study was to evaluate the anatomical variations in the morphology and architecture of lumbricals and to discuss its clinical implications. Subjects and Methods: This study was conducted on 74 disarticulated upper limbs during routine dissection of cadavers in the Department of Anatomy of MVJMC \& RH. The dissection was carried out based on the steps as per the Cunningham's manual. Results: Variations in lumbricals were observed in 12 specimens ( 8 in right side $\& 4$ in left side). The variation encountered were the proximal origin of lumbricals in 4 specimens $(5.41 \%)$, Split insertion in one specimen (1.35\%), bipennate second lumbrical in two specimens $(2.70 \%)$, accessory belly of first lumbrical in 4 specimens $(5.41 \%)$ and hypertrophied lumbrical in one specimen $(1.35 \%)$. Conclusion: Variations of the lumbrical can present with wide range of clinical presentations like compression of neurovascular structures as in hypertrophy, carpal tunnel syndrome as in proximal origin and accessory belly of lumbrical.

Keywords: Anomalous muscle, split insertion, proximal origin, bipennate, hypertrophy.

Corresponding Author: Dr. Sangeeta M, Professor \& HOD, Department of Anatomy, MVJ Medical College and Research Hospital, Hoskote, Bangalore, Karnataka, India.

Email: sangeetanatomy@gmail.com

Received: April 2020

Accepted: April 2020

Introduction

Lumbricals of the hand are worm like muscles arising from the four tendons of flexor digitorum profundus (FDP). They are four in number, first and second lumbrical arise from radial sides and palmar surface of tendons to index and middle fingers. The third and fourth lumbricals arise from adjacent sides of the tendons of middle and ring finger, ring and little finger respectively. They pass radially along the metacarpophalangeal joint (MCP) forming a tendon and at the level of dorsal surface of proximal phalanx, joining the radial margin of the dorsal digitorum expansion forming wing tendon. ${ }^{[1]}$

Variations in the lumbricals are common at the site of origin and insertion, architecture, accessory belly of first lumbrical and very rarely second lumbrical. ${ }^{[2-4]}$

The lumbrical muscles are unique in their functions in being only intrinsic muscles which bridges between the palmar and dorsal surface (Link muscle). They act as flexors at MCP joint and extensor at inter-phalangeal (IP) joint. This unique property endows them in performing fast, alternating movements and fine tuning digit motion. ${ }^{[5]}$

\section{Subjects and Methods}

This study was conducted on 74 disarticulated upper limbs (41 right \& 33 left) of unknown sexes during routine dissection of cadavers in the Department of Anatomy of MVJMC \& RH. The skin of front of forearm and palm was incised and reflected based on the steps as per the Cunningham's manual. Neurovascular structures in the palm were exposed after the reflection of superficial fascia and palmar aponeurosis. The tendons of flexor digitorum superficialis and profundus were cleaned to expose the lumbricals. The following parameters in the lumbricals were studied.

1) Site of origin (proximal or distal)

2) Insertion (normal or spilt)

3) Pennate pattern (unipennate or bipennate)

4) Presence of accessory belly.

5) Size (atrophy or hypertrophy)

\section{Results}

Out of 74 specimens dissected, 41 were of right side and 33 were of left side. Proximal origin of lumbricals was observed in 4 specimens out of which 3 were of right side and one from left side. Proximal origin was seen to arise from just above 
the flexor retinaculum. In 2 out of the 4 specimens, all the four lumbricals were seen to arise proximal to flexor retinaculum. In the remaining 2, the proximal origin of first lumbrical alone was observed in one specimen and proximal origin of 2nd, 3rd and 4th lumbrical was observed in other [Figure 1].

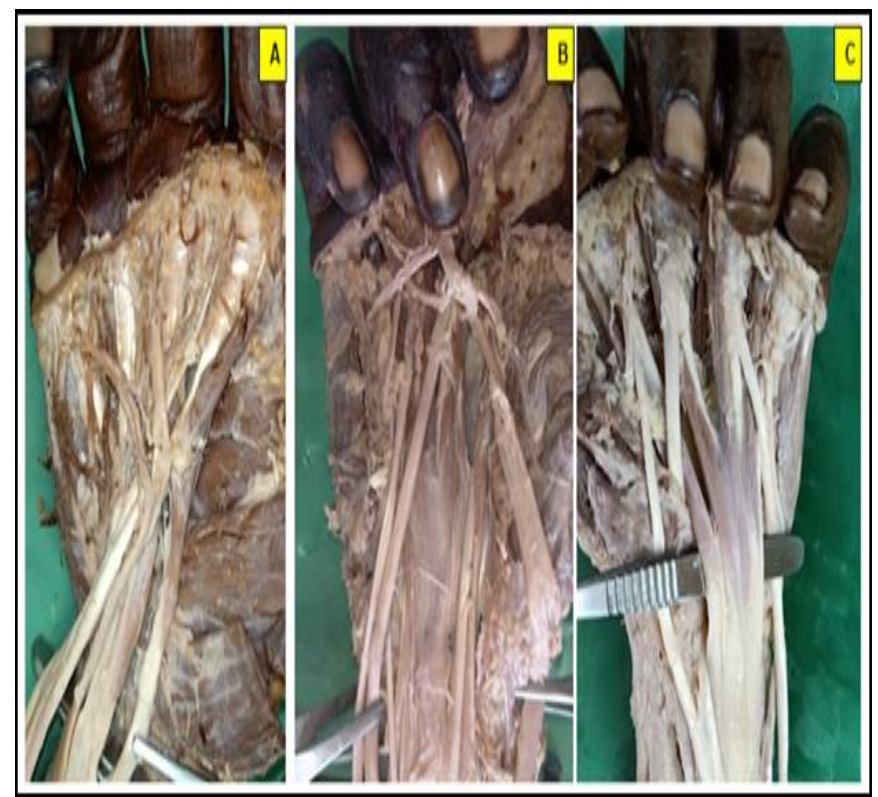

Figure 1: Shows the proximal origin of A) first lumbrical alone B) 2nd, 3rd \& 4th lumbrical C) all the four lumbrical

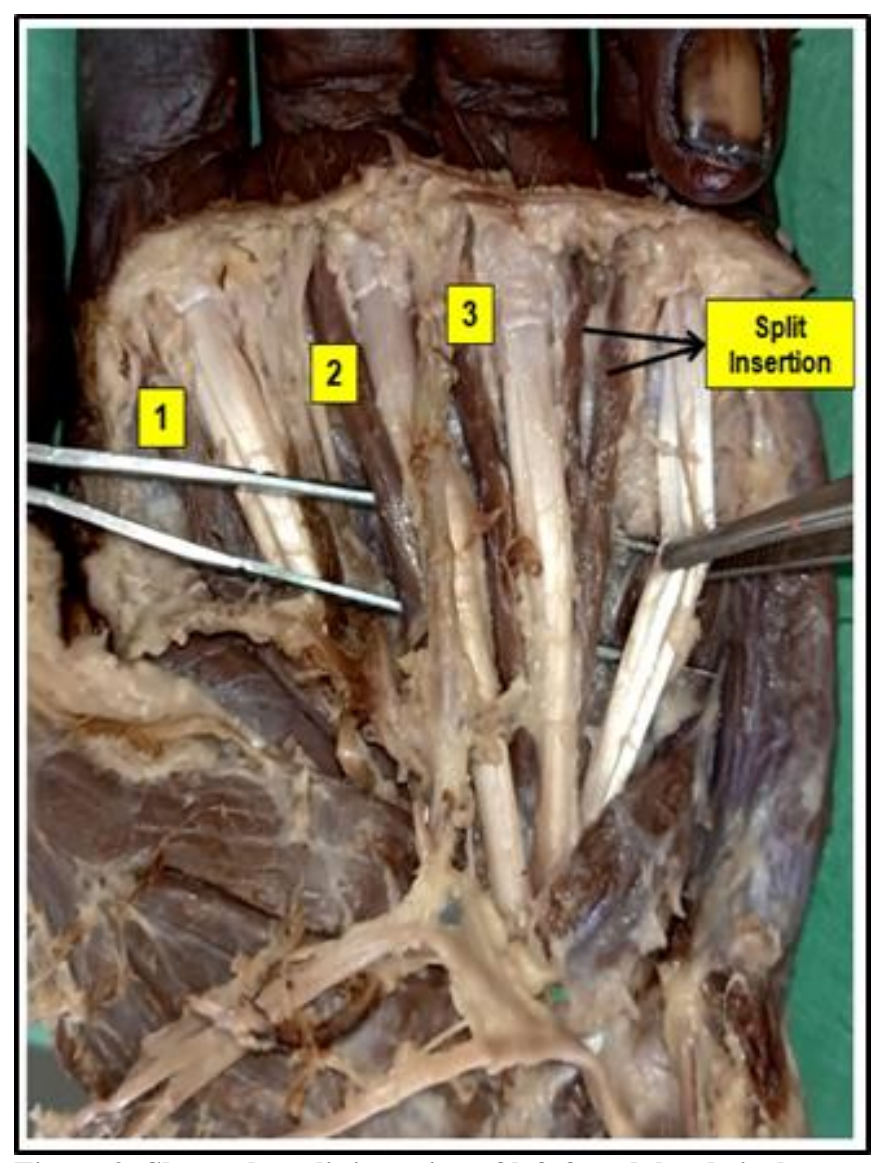

Figure 2: Shows the split insertion of left fourth lumbrical



Figure 3: shows the bipennate second lumbrical (right sided)

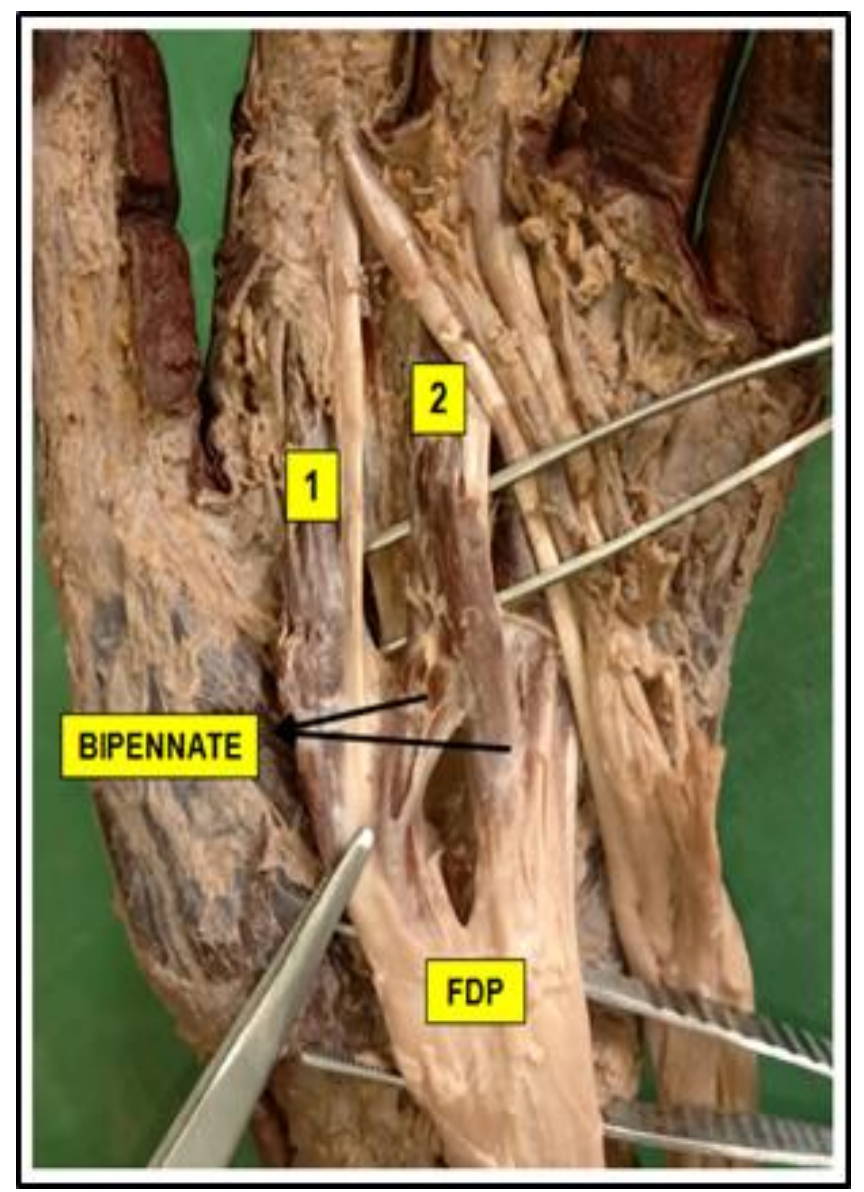

Figure 4: Shows the bipennate second lumbrical (left sided) 




Figure 5: shows the accessory belly of first lumbrical. *accessory belly, Black arrow- first lumbrical

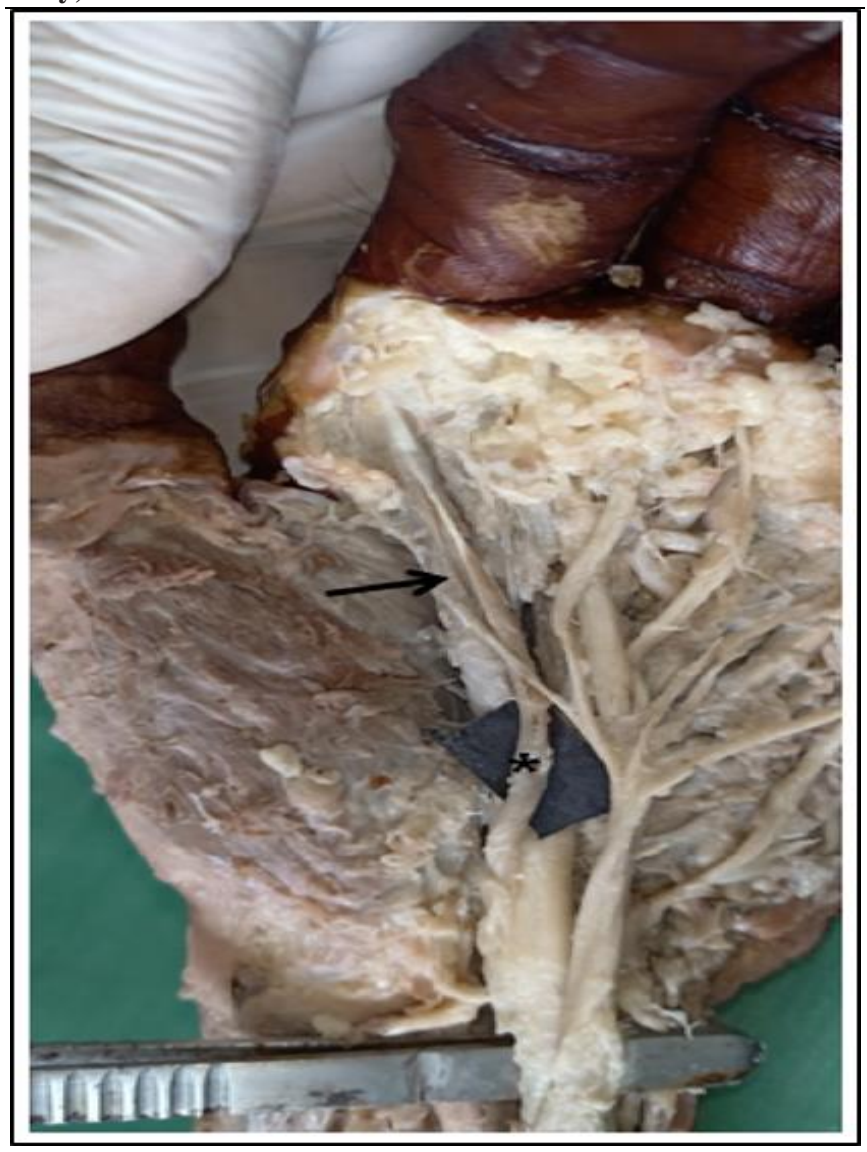

Figure 6: shows the accessory belly of first lumbrical. *accessory belly, Black arrow- first lumbrical

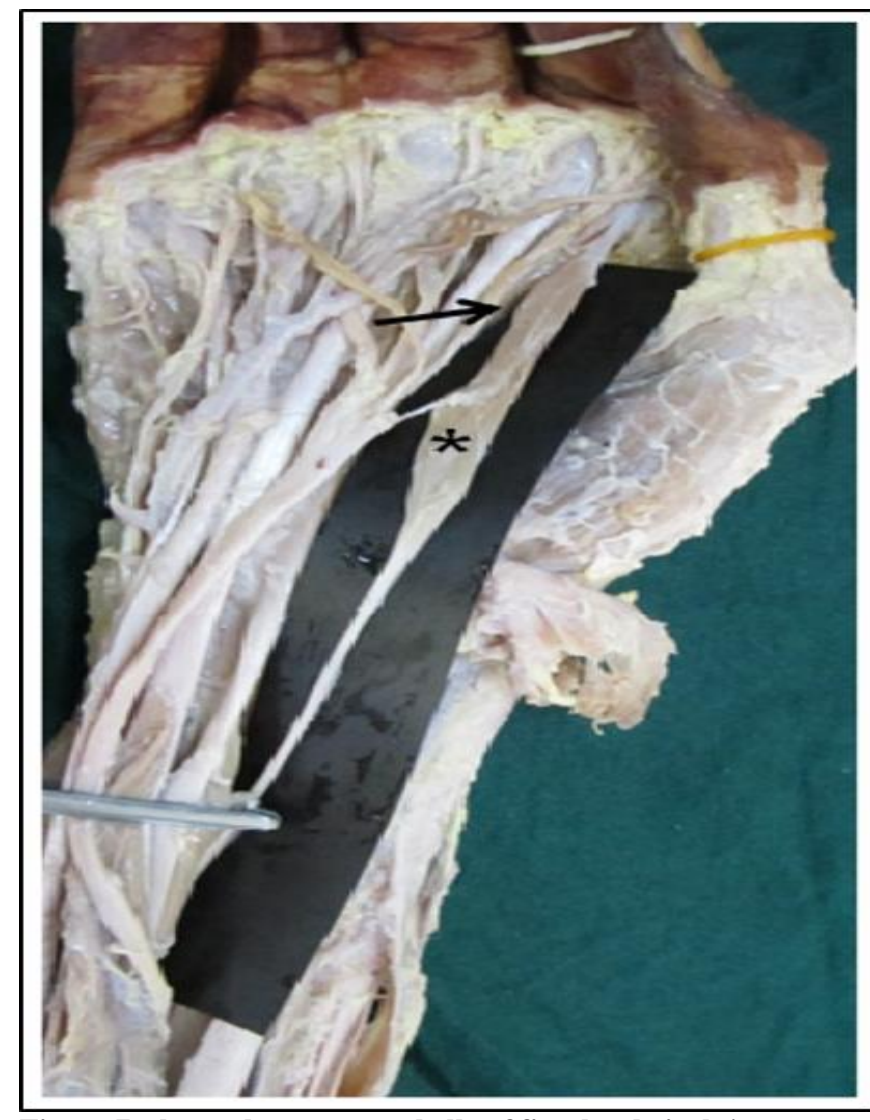

Figure 7: shows the accessory belly of first lumbrical. *accessory belly, Black arrow- first lumbrical

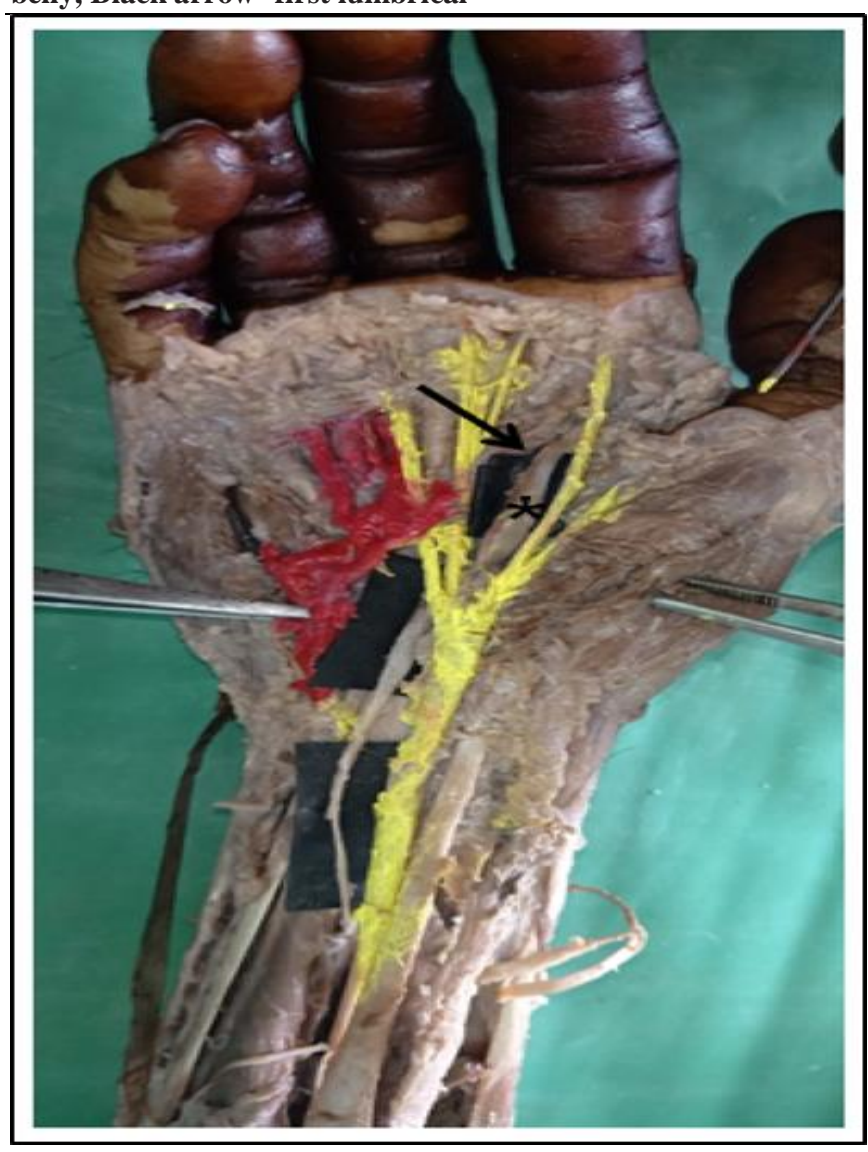

Figure 8: shows the accessory belly of first lumbrical. * accessory belly, Black arrow- first lumbrical 
Table 1: Incidence of variations of lumbricals based on laterality

\begin{tabular}{|l|l|l|}
\hline Lumbricals & $\begin{array}{l}\text { Right Hand } \\
\text { n=41 }\end{array}$ & $\begin{array}{l}\text { Left Hand } \\
\mathbf{n = 3 3}\end{array}$ \\
\hline Site of Origin & \multicolumn{2}{|l|}{} \\
\hline $\begin{array}{l}\text { Normal Origin or distal to flexor } \\
\text { reticulum }\end{array}$ & $38(92.7 \%)$ & $32(96.97 \%)$ \\
\hline Proximal origin & $3(7.3 \%)$ & $1(3.03 \%)$ \\
\hline Insertion & $41(100 \%)$ & $32(96.97 \%)$ \\
\hline Normal & $0(0 \%)$ & $1(3.03 \%)$ \\
\hline Spilt Insertion of 4th lumbrical & $1(2.44 \%)$ & $1(3.03 \%)$ \\
\hline Bipennate 2nd Lumbricals & $3(7.3 \%)$ & $1(3.03 \%)$ \\
\hline Accesory belly of 1st Lumbricals & $1(2.44 \%)$ & $0(0 \%)$ \\
\hline Hypertrphied Lumbrical &
\end{tabular}

Almost all the specimens showed the normal pattern of insertion except one which showed the spilt insertion of fourth lumbrical on the left side. The fourth lumbrical at its insertion split into two slips which got inserted into adjacent extensor expansion of the ring and little finger [Figure 2].

All the first lumbrical were unipennate. Variations were found only in the second lumbricals, 2 out of 74 specimens showed bipennate pattern one on each side. All the 3rd and $4^{\text {th }}$ lumbricals were bipennate [Figure $3 \& 4$ ].

Accessory belly of lumbricals was observed in 4 out of 74 specimens ( 3 right $\& 1$ left) studied. In all the 4 specimens, only the first lumbrical showed an accessory belly arising from distal belly of flexor digitorum superficialis and merging with the main muscle just proximal to its insertion (Figure 58) . All the accessory belly of first lumbricals were innervated by median nerve.

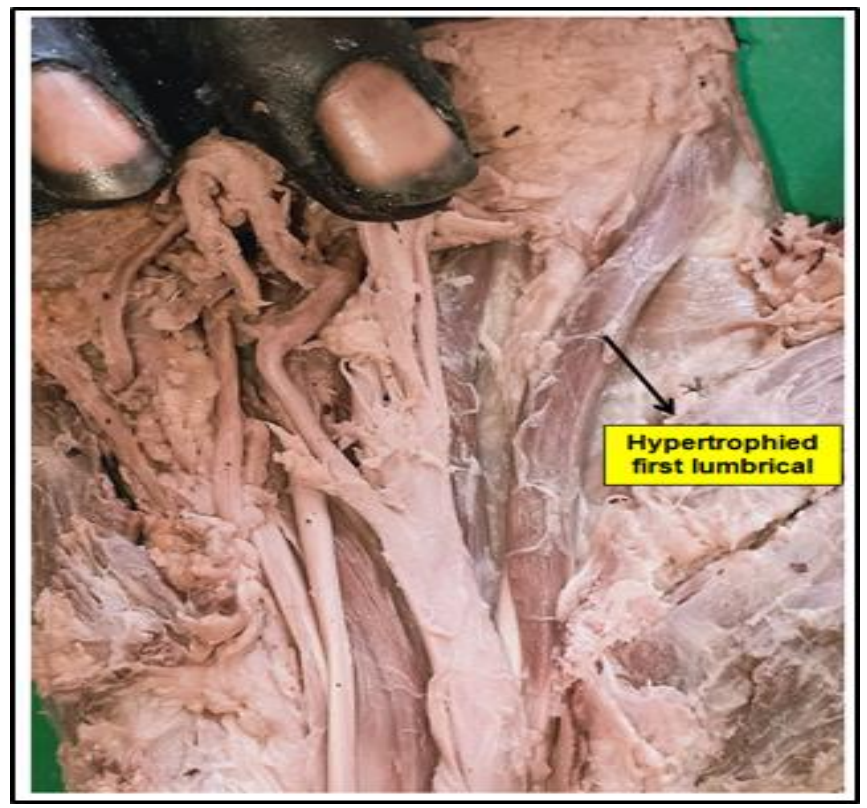

Figure 9: shows the hypertrophied first lumbrical

\section{Discussion}

Variations in the lumbrical muscle have been reported as early as 1961 by Mehta et al. They reported anomalous and additional origin of lumbricals from palm (adjacent FDP, same FDS \& metacarpal) and forearm (belly of FDP, FDS \& FPL) ${ }^{[6]}$ Similar variation in the palm was reported by Trivedi $S$ et al who observed a case of unusual origin of first lumbrical from the first tendon of FDS instead of FDP. ${ }^{[5]}$ In our present study, we did not observe any anomalous origin of the lumbrical in the palm, instead we observed the proximal high origin as well as additional origin from the forearm.

If the lumbrical were seen originating proximal to flexor retinaculum, we categorized it as high origin. In our study, the incidence of proximal origin was observed in 5.40\% (4 specimens). In 2 out of the 4 specimens, all the four lumbricals were seen to arise proximal to flexor retinaculum. In the remaining 2, the proximal origin of first lumbrical alone was observed in one specimen and proximal origin of $2 \mathrm{nd}$, 3 rd and 4th lumbrical was observed in other.

Incidence of accessory belly of lumbricals arising from the forearm was observed in 4 specimens which accounts for $5.40 \%$. In all the 4 specimens, only the first lumbrical showed an accessory belly arising from distal belly of flexor digitorum superficialis and merging with the main muscle just proximal to its insertion. All the accessory belly of first lumbricals were innervated by median nerve.

Similar observations have been reported by Koizumi (2002), Bhagath Kumar Potu (2006) and Soubhagya R Nayak (2008).$^{[4,7,8]}$ In contrast, Sawant SP have reported accessory belly of first lumbrical arising from radial side of tendon of index finger of FDP in addition to normal origin of first lumbrical. ${ }^{[9]}$ Rare case report of accessory belly of second lumbrical was reported by Bagoji I.B et al. ${ }^{[10]} \mathrm{He}$ reported that accessory belly of second lumbrical arising from ulnar side of tendon of FDP for index finger at the level of the proximal border of the flexor retinaculum.

All the accessory bellies had a central fleshy belly and proximal tendinous origin as well as distal tendinous insertion. The mean length of the first accessory lumbrical was $14 \mathrm{~cm}$, proximal tendon, distal tendon and muscle belly mean length being $6.5 \mathrm{~cm}, 2 \mathrm{~cm}$ and $5 \mathrm{~cm}$ respectively. All the accessory slip passed radially to the tendon of FDP merged with main muscle before getting inserted into dorsal digital expansion.

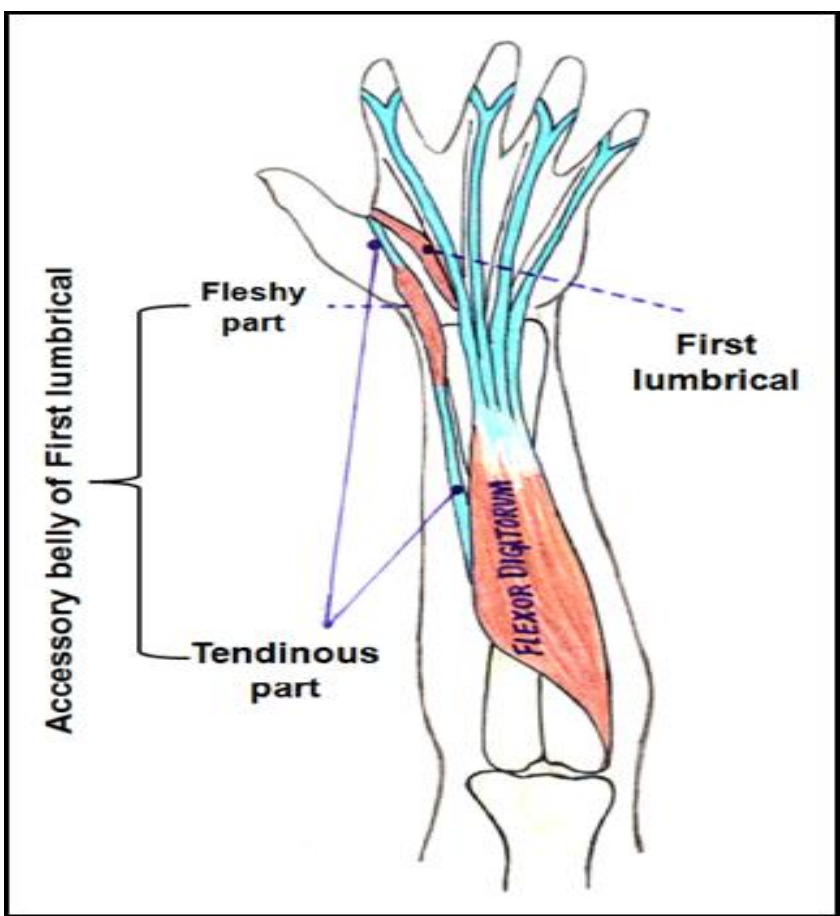

Figure 10: shows the schematic representation of parts of accessory belly of first lumbrical 
An embryological basis in respect to incidence of accessory belly of first lumbrical was explained by Koizumi et al \& Haines et al. Haines suggested FDS to be homologous with the intrinsic muscles of the palm and that the origin shifts proximally to forearm in mammals. Furthermore Koizumi et al. mentioned that the first lumbrical muscle and the distal muscle belly for the index finger of the FDS have an intimate relationship with each other, and have a common phylogenetic origin. ${ }^{[4,11]}$

Variation in the architecture was found in the form of bipennate 2nd lumbrical instead of the usual unipennate pattern. Similar finding was documented by Hosapatna $\mathrm{M}$ et al and Mutalik AM [Table 2]. ${ }^{[3,12]}$

Among the variations of lumbricals studied, split insertion is the commonest variation reported. Split Insertion was commonly encountered in 3 rd and 4 th lumbricals. Our results were in concordance with above studies showing the split insertion of 4th lumbrical [Table 3]. Split insertion is an atavistic condition presenting as doubling of muscles as in lower animals (Virginian oppsum). ${ }^{[13]}$

Table 2: shows the incidence of bipennate 2nd lumbrical in different studies.

\begin{tabular}{|l|l|l|}
\hline Authors & $\begin{array}{l}\text { No. of hand } \\
\text { Examined }\end{array}$ & $\begin{array}{l}\text { No. of Bipennate } \\
(\%)\end{array}$ \\
\hline Hosapatna M $(2013)^{[3]}$ & 30 & $1(3.33 \%)$ \\
\hline Mutalik AM $(2011)^{[12]}$ & 30 & $2(6.67 \%)$ \\
\hline Present Study $(2020)$ & 74 & $2(2.70 \%)$ \\
\hline
\end{tabular}

Table 3: shows the incidence of Split insertion of lumbricals in different studies.

\begin{tabular}{|l|l|l|l|l|}
\hline Authors & $\begin{array}{l}\text { Total no. of } \\
\text { hands }\end{array}$ & $\mathbf{2}^{\text {nd }}$ Lumbricals & $\mathbf{3}^{\text {rd }}$ Lumbricals & $\mathbf{4}^{\text {th }}$ Lumbricals \\
\hline Mehta and Gardner $(1961)^{[6]}$ & 75 & $1(1.3 \%)$ & $29(38.7 \%)$ & $6(8 \%)$ \\
\hline Singh et al $(1975)^{[14]}$ & 107 & - & $29(27.1 \%)$ & $27(25.2 \%)$ \\
\hline Mutalik AM(2011) $)^{[12]}$ & 30 & $8(26.67 \%)$ & - & $1(3.3 \%)$ \\
\hline Hosapatna M $(2013)^{[3]}$ & 30 & $1(3.3 \%)$ & - & - \\
\hline Parminder K (2013) & {$[2]$} & - & $14(28 \%)$ & $8(16 \%)$ \\
\hline Present Study & 50 & - & - & $1(1.35 \%)$ \\
\hline
\end{tabular}

It was observed in our study that first lumbrical was found to be more bulky than other lumbricals in most of the specimens. However, clear hypertrophy was observed in only one specimen [Figure 9]. Similar finding was documented by Hosapatna M et al (3.3\%). Such hypertrophy of first lumbrical can be attributed to overuse of thenar musculature as associated with fine movements involving thumbs and index finger. ${ }^{[3]}$

Such variations of the lumbrical can present with wide range of clinical presentations like compression of neurovascular structures as in hypertrophy, carpal tunnel syndrome as in proximal origin and accessory belly of lumbrical.

\section{Conclusion}

The accessory belly of lumbrical have mostly been documented as case reports, ours first of its kind to report this as the case study. This could be of both academic and clinical interest to vascular surgeons and orthopaedicians.

\section{References}

1. Datta AK. Essentials of Human Anatomy. 2nd Ed. Calcutta: Current Books International 1995.

2. Parminder K. Morphological study of lumbricals-a cadaveric study. Journal of clinical and diagnostic research: JCDR. 2013 Aug;7(8):1558.

3. Hosapatna M, Bangera H, Kumar N, Sumalatha S. Morphological Variations in Lumbricals of Hand-A Cadaveric Study. Plastic Surgery: An International Journal. 2013 Jun 23;23.

4. Koizumi M, Kawai K, Honma S, Kodama K. Anomalous lumbrical muscles arising from the deep surface of flexor digitorum superficialis muscles in man. Annals of Anatomy-Anatomischer Anzeiger. 2002 Jul 1;184(4):387-92.

5. Trivedi S, Satapathy BC, Rathore M, Sinha MB. A rare case of anomalous origin of first lumbrical from the tendon of flexor digitorum superficialis to index finger. Journal of clinical and diagnostic research: JCDR. 2016 Nov; 10 (11):AD03.

6. Mehta HJ, Gardner WU. A study of lumbrical muscles in the human hand. American Journal of Anatomy. 1961 Nov; 109 (3):227-38.

7. Potu B, Gorantla PT, Rao M, Vollala V, Nayak S. Anomalous origin of the first lumbrical in the hand and its possible role in Carpal Tunnel Syndrome. The Internet Journal of Neurology. 2006;8(1):13.

8. Nayak SR, Rathan R, Chauhan R, Krishnamurthy A, Prabhu LV. An additional muscle belly of the first lumbrical muscle. Cases journal. 2008 Dec;1(1):103.

9. Sawant SP. The cadaveric study of lumbricals of hand in 100 specimens. International Journal of Current Sciences. 2013; 6E:107.10 .

10. Bagoji IB, Doshi MA, Hadimani GA, Bannur BM, Rathod SB, Patil BG. An anomalous accessory muscle belly of the second lumbrical with bifurcated insertion of third lumbrical, and their relevance with carpal tunnel syndrome. Journal of Chemical and Pharmaceutical Research. 2014; 6(9):295-7.

11. Haines RW. The flexor muscles of the forearm and hand in lizards and mammals. Journal of Anatomy. 1950 Jan;84(Pt 1):13.

12. Mutalik AM. Morphological variations in the origin and insertion of lumbricals of the upper limb in cadavers. Journal of Clinical and Diagnostic Research. 2011 Apr;5(2):278-81.

13. McMurrich J.P. Phylogency of palmar musculature. Am J Anat. 1903; 2: 463-500

14. Singh JD, Raju PB, Singh S. Anomalous insertion of hand lumbricals. J Anat Soc Ind. 1975;24(3):122-25. 
Copyright: (C) the author(s), 2020. It is an open-access article distributed under the terms of the Creative Commons Attribution License (CC BY 4.0), which permits authors to retain ownership of the copyright for their content, and allow anyone to download, reuse, reprint, modify, distribute and/or copy the content as long as the original authors and source are cited.

How to cite this article: Afroze MKH, Sangeeta M, Varalakshmi KL. Revisiting the Morphological Variations in Lumbricals of Hand. Acad. Anat. Int. 2020;6(1):43-48.

DOI: dx.doi.org/10.21276/aanat.2020.6.1.10 